\title{
ANALISIS AISAS (ATTENTION, INTEREST, SEARCH, ACTION, SHARE) PADA PENGUNJUNG THE LODGE MARIBAYA LEMBANG
}

\author{
Gina Amalia, Fahrurazy Darmawan, dan Yuwana M. Marjuka \\ Fakultas Pariwisata, Universitas Pancasila Jakarta \\ Srengseng Sawah, Jagakarsa, Jakarta Selatan 12640, Indonesia
}

\begin{abstract}
The attractions in West Bandung district these days are in great demand by the tourists, one of them being The Lodge Maribaya. The Lodge Maribaya is located in Cibodas Village, Lembang sub-district. The popularity of The Lodge Maribaya is also thanks to the implementation of effective and efficient marketing communications. One of them is through internet marketing communication. This tourists' convenience in searching tour destination is the one that creates the AISAS (attention, interest, search, action, share) model. The purpose of this research is to analyze the application of AISAS model according to Sugiyama (2011) towards The Lodge Maribaya Lembang's visitors. The method used is qualitative research with there search focus being the application of the visitors' AISAS using the data reduction, data display and conclusion This research needs 100 respondent samples which are the visitors of The Lodge Maribaya. According to the result of data processing, it is known that the attention, interest, search, action and share stage as a whole gets 90,5\% percentage. With that being said, this research shows that most of The Lodge Maribaya's visitors has applied the AISAS model in their visiting behavior.
\end{abstract}

Keywords: The Lodge Maribaya, Marketing Communication Planning, AISAS.

\section{PENDAHULUAN}

The Lodge Maribaya yang terletak di Desa Cibodas, Kecamatan Lembang. The Lodge Maribaya merupakan destinasi wisata yang menyajikan atraksi photo spots yang berlatarkan pemandangan alam pertama di Jawa Barat sudah dilengkapi dengan fasilitas menarik yang dapat dinikmati oleh para pencinta kegiatan outdoor. The Lodge Maribaya memiliki area camping dengan tenda unik berbentuk labu yang disewakan, villa, restoran, area makan layaknya food stall, playground, dan juga memfasilitasi wisatawan dengan berbagai macam photo spots seperti: Sky Tree, Zip Bike, Mountain Swing, Gantole, Hot Air Balloon Dan Sky Plane (thelodgemaribaya.com).

Pada akhir pekan, The Logde Maribaya dikunjungi 5.000-6.000 wisatawan per hari (APKASI.org). Wisatawan yang datang bukan hanya dari Lembang dan Bandung tapi juga dari berbagai macam daerah. Kepopuleran The Lodge Maribaya ini juga berkat implementasi komunikasi pemasaran yang efektif dan efisien. Salah satunya adalah melalui internet marketing communication, yang dimana sebelum berkunjung wisatawan dapat melihat dan mengetahui informasi mengenai The Lodge Maribaya melalui internet.

Setiap destinasi wisata perlu perencanaan jangka panjang untuk memenuhi kebutuhan wisatawannya. Menurut Gunn dan Varr (2002) elemen destinasi berupa atraksi, transportasi, jasa, informasi dan promosi. Perencanaan destinasi wisata bukan hanya perencanaan spasialnya (fisik), namun perencanaan non-spasial seperti perencanaan pemasaran di internet maupun di media sosial pun perlu diperhatikan, dan hal tersebut termasuk dalam elemen informasi yang nantinya akan memudahkan wisatawan dalam mengetahui tentang bagaimana produk, layanan dan iklan yang dibuat oleh destinasi wisata yang akan mereka datangi.

Pada era digitan saat ini, wisatawan semakin mudah mengakses informasi produk yang mereka cari menggunakan internet dan media sosial khususnya mencari dan merencanakan perjalanan wisatanya. Kemudahan wisatawan dalam mencari destinasi wisata inilah yang melahirkan model AISAS (attention, interest, search, action, share). Oleh karena itu, akan diteliti sejauh mana model AISAS yang diterapkan oleh pengunjung dalam melakukan perjalanan wisata ke The Lodge Maribaya Lembang.

\section{TINJAUAN PUSTAKA}

\section{Perencanaan pariwisata}

Perencanaan pariwisata merupakan perencanaan yang mempertimbangkan semua sumber daya pariwisata, organisasi, pasar, dan program di suatu daerah. Begitu pula perencanaan produk pariwisata harus dimulai dari memahami pasar dan memahami keunikan sumberdaya, karena minat dan perilaku pasar selalu berkembang maka produk pariwisata yang ditawarkan akan selalu berkembang, demikian pula dengan bentuk pemasarannya (Hermantoro, 2015).

Dalam penelitian ini komunikasi pemasaran juga termasuk dalam perencanaan pariwisata karena sistem informasi pemasaranadalah sistem informasi yang mendukung perencanaan, kontrol dan pemrosesan transaksi yang dibutuhkan untuk penyelesaian 
aktivitas pemasaran seperti penjualan, advertising dan promosi (Jogiyanto. 2009).

\section{Komunikasi Pemasaran}

Komunikasi pemasaran (marketing communication) adalah sarana perusahaan yang berusaha untuk menginformasikan, membujuk, dan mengingatkan konsumen (secara langsung atau tidak langsung) tentang produk dan merek yang mereka jual. Dalam arti, komunikasi pemasaran merupakan suara dari perusahaan dan merek. Dengan memperkuat loyalitas pelanggan, komunikasi pemasaran dapat berkontribusi ekuitas pelanggan (Kotler dan keller, 2013).

Pemasaran internet merupakan jalan terkuat untuk membangun merek, memulai dan memperkuat hubungan dengan pelanggan. Namun, pemasar online harus semakin pintar untuk mendesain dan menghantarkan pesan merek yang menangkap dan mempértahankan perhatian pelanggan. Strauss dan Frost (2014) mendefinisikan komunikasi pemasaran terintegrasi sebagai proses lintas fungsional untuk merencanakan, melaksanakan, dan memantau komunikasi pemasaran dirancang untuk profitabilitas memperoleh, mempertahankan, dan menumbuhkan pelanggan. Komunikasi pemasaran terintegrasi merupakan lintas fungsional karena setiap titik sentuh yang dimiliki pelanggan dengan perusahaan atau agennya membantu untuk membentuk citra merek.

\section{AISAS (Attention, Interest, Search, Action, Share )}

Ketika membutuhkan barang dengan keterlibatan yang tinggi, pelanggan akan melakukan pencarían yang lebih mendalam dibandingkan barang-barang dengan keterlibatan yang rendah. Oleh karena itu, Dentsu (2004) dalam sugiyama dan Andree (2011) mengemukakan sebuah model komunikasi pemasaran yang didapat dari perkembangan teknologi, yang diberi nama dengan model AISAS. Jika dibandingkan model ini ke AIDMA, maka akan dilihat bahwa proses transormasi psikologis (Action, Interest, Desire, Memory) telah disederhanakan menjadi Action dan Interest saja. Kemudian yang terakhir untuk proses Action telah diperluas untuk mencakup Search $\rightarrow$ Action $\rightarrow$ Share. Sehingga model tersebut menjadi: Attention $\rightarrow$ Interest $\rightarrow$ Search $\rightarrow$ Action $\rightarrow$ Share.

Model AISAS yang dikembangkan untuk menilik tingkah laku wisatawan berdasarkan pemahaman bahwa internet menjadi besar, dan bahwa wisatawan saat ini memiliki akses pada lingkungan dimana mereka mendapatkan dan mengirimkan informasi. Pada model ini, proses kuncinya pada Gambar 2.4 yaitu: Attention, yaitu wisatawan pertama kali melihat produk atau iklan, diikuti oleh Interest, yaitu ketertarikan setelah melihat produk atau iklan tersebut. Setelahnya, wisatawan mencari (Search) informasi, lalu melakukan kunjungan (Action), kemudian informasi tersebut dibagikan (Share) ke calon wisatawan lain.

\section{METODE PENELITIAN}

Penelitian ini menggunakan metode penelitian kualitatif dimana datanya diambil melalui proses penyebaran kuesioner terhadap wisatawan yang berkunjung ke The Lodge Maribaya guna memperoleh hasil yang akurat dan informatif guna proses pembahasan penelitian. Metode pengumpulan data berupa observasi, kuesioner dan dokumentasi. Sampel penelitian ini adalah 100 pengunjung yang dipilih secara acak. Penelitian ini menggunakan pengukuran skala likert dan teknik análisis yang digunakan dalam penelitian ini adalah teknik analisis model Miles dan Huberman (1984) dalam Sugiyono (2017), yang dilakukan dengan tiga tahap yaitu data reduction, data display, dan coclusion. 
Tabel 1 Variabel dan Sumber Data

\begin{tabular}{|c|c|c|c|}
\hline Sub-variabel & Indikator & Sumber data & $\begin{array}{c}\text { Teknik } \\
\text { pengumpulan data }\end{array}$ \\
\hline $\begin{array}{l}\frac{\text { Attention }}{\text { Khalayak memperhatikan }} \\
\text { produk, layanan, dan iklan } \\
\text { (sugiyama dan Andree, } \\
\text { 2011). }\end{array}$ & 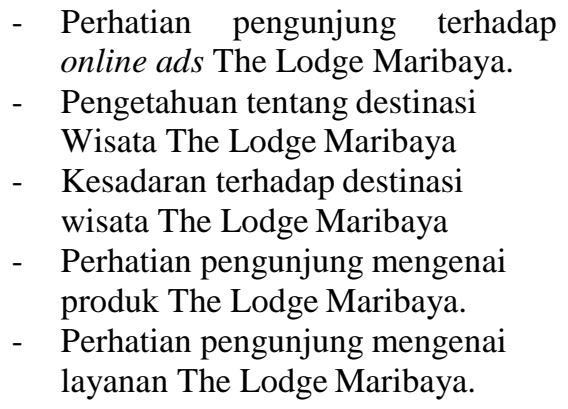 & Pengunjung & $\begin{array}{l}\text { Observasi dan } \\
\text { Kuesioner }\end{array}$ \\
\hline \begin{tabular}{l}
\multicolumn{3}{l}{ Interest } \\
Sikap tertarik oleh khalayak \\
terhadap produk atau \\
layanan yang \\
dilihatnya (sugiyama dan \\
Andree, 2011).
\end{tabular} & $\begin{array}{ll}\text { - } & \text { Alasan ketertarikan terhadap } \\
\text { destinasi } & \text { wisata The Lodge } \\
\text { Maribaya } & \end{array}$ & Pengunjung & $\begin{array}{l}\text { Observasi dan } \\
\text { Kuesioner }\end{array}$ \\
\hline $\begin{array}{l}\text { Search } \\
\text { Pencarian dan pengumpulan } \\
\text { informasi oleh konsumen } \\
\text { dalam rangka mempelajari } \\
\text { produk atau layanan terlebih } \\
\text { dahulu (Sugiyama dan } \\
\text { Andree, 2011). }\end{array}$ & $\begin{array}{l}\text { - Pencarian informasi The Lodge } \\
\text { Maribaya melalui internet. } \\
\text { - Pengetahuan mengennai lokasi } \\
\text { dan harga the lodge maribaya }\end{array}$ & Pengunjung & $\begin{array}{l}\text { Observasi dan } \\
\text { Kuesioner }\end{array}$ \\
\hline $\begin{array}{l}\frac{\text { Action }}{\text { Tindakan konsumen terkait }} \\
\text { dengan aktivitas pembelian } \\
\text { produk atau layanan } \\
\text { (Sugiyama dan Andree, } \\
\text { 2011). }\end{array}$ & $\begin{array}{l}\text { - Keputusan berkunjung berdasarkan } \\
\text { informasi mengenai The Lodge } \\
\text { Maribaya. } \\
\text { - Keputusan berkunjung terkait } \\
\text { harga, jarak, fasilitas dan Observasi } \\
\text { dan Kuesioner pemandangan alam } \\
\text { Observasi dan Kuesioner menuju } \\
\text { ke The Lodge Observasi dan } \\
\text { Kuesioner Maribaya.. } \\
\text { Tindakan terkait atraksi wisata } \\
\text { photo spots yang ada di The Lodge } \\
\text { Maribaya. }\end{array}$ & Pengunjung & $\begin{array}{l}\text { Observasi dan } \\
\text { Kuesioner }\end{array}$ \\
\hline $\begin{array}{lr}\text { Share } & \\
\text { Tindakan berupa } & \text { membagi } \\
\text { informasi } & \text { dan } \\
\text { pengalamannya } & \text { tentang } \\
\text { produk atau } & \text { layanan } \\
\text { (Sugiyama dan } & \text { Andree, } \\
2011) . & \end{array}$ & 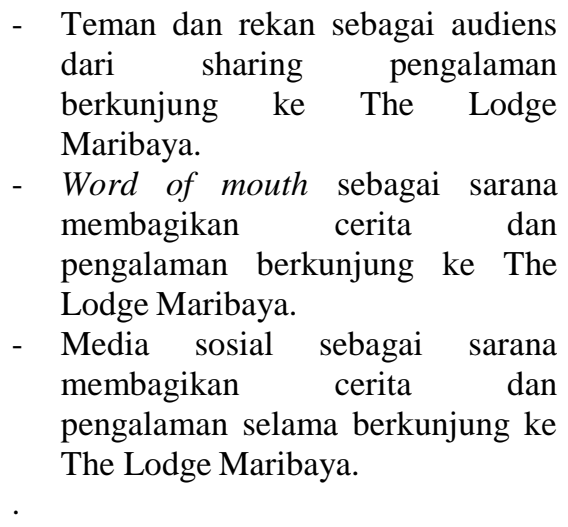 & Pengunjung & $\begin{array}{l}\text { Observasi dan } \\
\text { Kuesioner }\end{array}$ \\
\hline
\end{tabular}




\section{HASIL DAN PEMBAHASAN}

\section{Gambaran Umum Penelitian}

The Lodge Maribaya Lembang merupakan destinasi wisata yang sedang memiliki ketertarikan menengah keatas di mata para wisatawan. The lodge maribaya adalah destinasi pertamadi Jawa Barat yang mengusung konsep berfoto di ketinggian dengan latar hamparan alam yang sangat indah.Perkembangan yang pesat dan menghasilkan banyaknya kunjungan wisatawan ke TLM tidak lepas dari perencanaan pemasaran yang melibatkan dan memanfaatkan internet dan media sosial sebagai sarana penyebaran informasi. Penyebaran informasi melalui internet dan media sosial akan sangat cepat menjangkau kawasan yang luas. Selain itu, pengguna internet pun semakin mudah mencari informasi mengenai destinasi wisata yang sedang populer yaitu The Lodge Maribaya Lembang. Kemudahan pengguna dalam mencari informasi mengenai harga, fasilitas, jarak dan atraksi apa saja yang ada di destinasi tersebut inilah yang menghasilkan model AISAS (attention, interest, search, action, share).

Model AISAS merupakan sebuah model komunikasi pemasaran yang didapat dari perkembangan teknologi dan digunakan untuk menilik perilaku wisatawan berdasarkan pemahaman bahwa wisatawan saat ini memiliki akses untuk mendapatkan dan mengirimkan informasi melalui internet. Dalam konteks ini, model AISAS sering digunakan oleh wisatawan yang ingin berkunjung ke The Lodge Maribaya dengan melakukan tahap-tahap mengetahui destinasi tersebut, selanjutnya wisatawan mulai tertarik untuk mengetahui lebih jauh tentang destinasi TLM, setelah itu mereka melakukan pencarían informasi mengenai The Lodge Maribaya yang kemudian menjadi sebuah keputusan untuk melakukan pembelian. Setelah itu, wisatawan menjadi penyampai informasi kepada orang lain melalui percakapan langsung maupun melalui internet dan media sosial.

Wisatawan yang berkunjung ke The Lodge Maribaya sebagian besar sudah menerapkan model perilaku wisatawan secara online ini, karena wisatawan yang berkunjung kebanyakan adalah seorang pelajar dan mahasiswa yang memang sangat up-to-date mengenai informasi baru yang tersebar di internet. The Lodge Maribaya banyak memasang iklan di internet maupun di media sosial, dibantu oleh wisatawan yang membagikan cerita dan mengunggah foto maupun video sehingga banyak orang yang mengetahui kemudian ingin untuk berkunjung ke The Lodge Maribaya sebagai tujuan utama.

\section{Karakteristik Responden}

Tabel 4.1 Jenis Kelamin Responden

\begin{tabular}{|c|c|c|}
\hline Jenis Kelamin & Frekuensi & $\begin{array}{c}\text { Persentase } \\
\text { Frekuensi }\end{array}$ \\
\hline Perempuan & 67 & $67 \%$ \\
\hline Laki-Laki & 33 & $33 \%$ \\
\hline Total & $\mathbf{1 0 0}$ & $\mathbf{1 0 0 \%}$ \\
\hline
\end{tabular}

Berdasarkan tabel 4.2, responden terbanyak yang diteliti adalah yang berjenis kelamin peremouan sebanyak 67 orang atau $67 \%$. Sedangkan sisanya adalah laki-laki sebanyak 33 orang atau $33 \%$.

Karakteristik berikutnya yang akan diolah adalah usia responden.

Tabel 4.2 Usia Responden

\begin{tabular}{|c|c|c|}
\hline $\begin{array}{c}\text { Usia } \\
\text { Responden }\end{array}$ & Frekuensi & $\begin{array}{c}\text { Persentase } \\
\text { Freakuensi }\end{array}$ \\
\hline$<20$ Tahun & 14 & $14.0 \%$ \\
\hline 21 - 30 Tahun & 64 & $64.0 \%$ \\
\hline 31 - 40 Tahun & 17 & $17.0 \%$ \\
\hline$>$ 40 Tahun & 5 & $5.0 \%$ \\
\hline Total & $\mathbf{1 0 0}$ & $\mathbf{1 0 0 . 0 \%}$ \\
\hline
\end{tabular}

Tabel 4.3 menujukkan bahwa usia yang diidentifikasi dari 100 sampel responden berada diantara $<20->40$ tahun. Hal tersebut dikarenakan mayoritas yang berkunjung ke The Lodge Maribaya adalah pelajar dan mahasiswa.

Tabel 4.3 Asal Tempat Tinggal

\begin{tabular}{|c|c|c|}
\hline $\begin{array}{c}\text { Asal Tempat } \\
\text { Tinggal }\end{array}$ & Frekuensi & $\begin{array}{c}\text { Persentase } \\
\text { Frekuensi }\end{array}$ \\
\hline Lembang & 11 & $11.0 \%$ \\
\hline $\begin{array}{c}\text { Bandung dan } \\
\text { sekitarnya }\end{array}$ & 19 & $19.0 \%$ \\
\hline Jawa Barat & 25 & $25.0 \%$ \\
\hline Luar Jawa Barat & 45 & $45.0 \%$ \\
\hline Total & $\mathbf{1 0 0}$ & $\mathbf{1 0 0 . 0 \%}$ \\
\hline
\end{tabular}


Tabel 4.4 menunjukkan bahwa dari ke-100 sampel responden yang berkunjung ke The Lodge Maribaya tersebut, sebanyak 45 orang atau 45,0\% diantaranya berasal dari luar Jawa Barat.

Tabel 4.4 Pekerjaan Responden

\begin{tabular}{|c|c|c|}
\hline Pekerjaan & Frekuensi & $\begin{array}{c}\text { Persentase } \\
\text { Frekuensi }\end{array}$ \\
\hline Wiraswasta & 18 & $18.0 \%$ \\
\hline Swasta & 30 & $30.0 \%$ \\
\hline PNS/TNI/POLRI & 5 & $5.0 \%$ \\
\hline Pelajar/Mahasiswa & 47 & $47.0 \%$ \\
\hline Lainnya & 0 & $0.0 \%$ \\
\hline Total & $\mathbf{1 0 0}$ & $\mathbf{1 0 0 . 0 \%}$ \\
\hline
\end{tabular}

Pada tabel 4.5, responden yang berkunjung ke The Lodge Maribaya paling tinggi didominasi oleh pelajar dan mahasiswa yaitu sebanyak 47 orang atau $47.0 \%$ dari 100 sampel responden.

Tabel 4.5 Pengahasilan Per Bulan

\begin{tabular}{|c|c|c|}
\hline $\begin{array}{c}\text { Pendapatan Per } \\
\text { Bulan }\end{array}$ & Frekuensi & $\begin{array}{c}\text { Persentase } \\
\text { Frekuensi }\end{array}$ \\
\hline < Rp. 3.000.000 & 56 & $56.0 \%$ \\
\hline $\begin{array}{c}\text { Rp. 3.000.000 - Rp. } \\
5.000 .000\end{array}$ & 39 & $39.0 \%$ \\
\hline$>$ Rp. 5.000.000 & 5 & $5.0 \%$ \\
\hline Total & $\mathbf{1 0 0}$ & $\mathbf{1 0 0 . 0 \%}$ \\
\hline
\end{tabular}

Berdasarkan tabel 4.6 responden terbanyak berada di kategori penghasilan di bawah Rp.3.000.000 per bulan dengan frekuensi sebesar 56 atau $56.0 \%$ dari keseluruhan responden penelitian. Dikarenakan yang berkunjung ke The Lodge Maribaya didominasi oleh pelajar dan mahasiswa maka penghasilannya pun masih di kategori tersebut.

Selanjutnya identifikasi frekusensi kunjungan responden ke The Lodge Maribaya.

Tabel 4.6 Frekuensi Kunjungan

\begin{tabular}{|c|c|c|}
\hline Kunjungan ke TLM & Frekuensi & Persentase Frekuensi \\
\hline Pertama kali & 82 & $82.0 \%$ \\
\hline $2-5 \mathrm{Kali}$ & 18 & $18.0 \%$ \\
\hline$>5 \mathrm{Kali}$ & 0 & $0.0 \%$ \\
\hline Total & 100 & $100.0 \%$ \\
\hline
\end{tabular}

Berdasarkan tabel 4.7, responden yang berkunjung ke The Lodge Maribaya baru pertama kali dengan frekuensi 82 orang responden atau $82 \%$ dari keseluruhan responden yang diteliti.

Tabel 4.7 Teman berkunjung

\begin{tabular}{|c|c|c|}
\hline Kategori & Frekuensi & $\begin{array}{c}\text { Persentase } \\
\text { Frekuensi }\end{array}$ \\
\hline Sendiri & 0 & $0.0 \%$ \\
\hline Teman/Keluarga & 97 & $97.0 \%$ \\
\hline Tour Travel & 3 & $3.0 \%$ \\
\hline Total & $\mathbf{1 0 0}$ & $\mathbf{1 0 0 . 0 \%}$ \\
\hline
\end{tabular}

Berdasarkan tabel 4.8, sebanyak 97 orang atau $97 \%$ dari keseluruhan responden yang diteiliti berkunjung ke The Lodge Maribaya bersama teman atau keluarga. Sedangkan sebanyak $3 \%$ menggunakan jasa tour travel.

Kemudian karakteristik responden dilihat dari moda transportasi yang digunakan untuk berkunjung ke The Lodge Maribaya.

Tabel 4.8 Moda transportasi yang digunakan

\begin{tabular}{|c|c|c|}
\hline Kategori & Frekuensi & $\begin{array}{c}\text { Persentase } \\
\text { Frekuensi }\end{array}$ \\
\hline Jalan Kaki & 0 & $0.0 \%$ \\
\hline Motor/Mobil & 87 & $87.0 \%$ \\
\hline Angkutan umum & 13 & $13.0 \%$ \\
\hline Total & $\mathbf{1 0 0}$ & $\mathbf{1 0 0 . 0 \%}$ \\
\hline
\end{tabular}

Berdasarkan tabel 4.9, moda transportasi yang digunakan oleh responden kebanyakan adalah motor atau mobil dengan frekuensi $87 \%$ dari keseluruhan responden yang diteliti. Sedangkan $13 \%$ menggunakan angkutan umum seperti transportasi online.

Tabel 4.9 Waktu yang dihabiskan responden untuk melewati proses AISAS (Attention, Interest, Search, Action, Share).

\begin{tabular}{|c|c|c|}
\hline Kategori & Frekuensi & Persentase (\%) \\
\hline$<5$ Hari & 46 & $46.0 \%$ \\
\hline 6 - 15 Hari & 18 & $18.0 \%$ \\
\hline 16 - 30 Hari & 15 & $15.0 \%$ \\
\hline > 30 Hari & 21 & $21.0 \%$ \\
\hline Total & $\mathbf{1 0 0}$ & $\mathbf{1 0 0 . 0 \%}$ \\
\hline
\end{tabular}


Berdasarkan tabel 4.10, kebanyakan responden menghabiskan waktu kurang dari 5 hari dalam melewati proses AISAS. Proses AISAS mencakup memperhatikan iklan, respon tertarik

\section{Hasil pembahasan pada sub-variabel Attention}

Hasil analisis attention pada pengunjung The Lodge Maribaya Lembang berdasarkan rekap data tanggapan responden terhadap ketiga pernyataan terhadap destinasi, mencari dan menelusuri informasi, memutuskan berkunjung, sampai dengan menyebarkan informasi dan pengalaman terkait destinasi yang mereka kunjungi.

terkait sub-variabel attention (item 1-3).Berikut ini adalah rekap data tanggapan responden terhadap ketiga pernyataan dari attention.

Tabel 4.10Analisis tanggapan Attention

\begin{tabular}{|c|c|c|c|c|c|c|c|c|}
\hline \multirow{2}{*}{ Pernyataan } & \multicolumn{5}{|c|}{ Tanggapan Responden } & \multirow{2}{*}{$\begin{array}{l}\text { Jumlah } \\
\text { Sampel }\end{array}$} & \multirow{2}{*}{$\begin{array}{l}\text { Skor } \\
\text { Total }\end{array}$} & \multirow{2}{*}{$\begin{array}{l}\text { Skor } \\
\text { Ideal }\end{array}$} \\
\hline & $\begin{array}{l}\text { SS } \\
\text { (5) }\end{array}$ & $\begin{array}{c}S \\
(4)\end{array}$ & $\begin{array}{l}\mathrm{RG} \\
(3)\end{array}$ & $\begin{array}{l}\mathrm{TS} \\
(2)\end{array}$ & $\begin{array}{c}\text { STS } \\
(1)\end{array}$ & & & \\
\hline \multirow{2}{*}{$\begin{array}{l}\text { Saya melihat destinasi wisata The } \\
\text { Lodge Maribaya melalui online ads } \\
\text { (Website, Blog, atau Social Media). }\end{array}$} & 91 & 9 & 0 & 0 & 0 & 100 & 491 & \multirow{2}{*}{500} \\
\hline & $91 \%$ & $9 \%$ & $0 \%$ & $0 \%$ & $0 \%$ & $100 \%$ & $98.2 \%$ & \\
\hline \multirow{2}{*}{$\begin{array}{l}\text { Saya mulai mengetahui berbagai } \\
\text { macam atraksi wisata di The Lodge } \\
\text { Maribaya. }\end{array}$} & 80 & 20 & 0 & 0 & 0 & 100 & 480 & \multirow{2}{*}{500} \\
\hline & $8 \%$ & $20 \%$ & $0 \%$ & $0 \%$ & $0 \%$ & $100 \%$ & $96.0 \%$ & \\
\hline \multirow{2}{*}{$\begin{array}{l}\text { Iklan The Lodge Maribaya } \\
\text { membantu saya dalam mengingatkan } \\
\text { beberapa atraksi unggukan pada } \\
\text { destinasi tersebut. }\end{array}$} & 79 & 18 & 0 & 3 & 0 & 100 & 467 & \multirow{2}{*}{500} \\
\hline & $79 \%$ & $18 \%$ & $0 \%$ & $3 \%$ & $0 \%$ & $100 \%$ & $93.4 \%$ & \\
\hline \multicolumn{7}{|c|}{ Total skor } & 1438 & \multirow{2}{*}{1500} \\
\hline \multicolumn{7}{|c|}{ Presentase } & $95,9 \%$ & \\
\hline
\end{tabular}

Berdasarkan perhitungan pada tabel 4.10 , tingkat attention paling tinggi ada pada ítem nomor satu sebanyak $98,2 \%$ bahwa wisatawan kebanyakan melihat destinasi wisata The Lodge Maribaya melalui online ads (Website, Blog, atau Social Media). Kemudian di posisi kedua tertinggi ada pada item nomor dua sebesar $96,0 \%$ yang menyatakan bahwa wisatawan mulai mengetahui atraksi wisata di The Lodge Maribaya. Selanjutnya pada ítem nomor tiga sebesar 93,4\% menyatakan bahwa iklan yang tersebar di online ads mengenai The Lodge Maribaya membantu mengingatkan wisatawan terhadap beberapa atraksi unggulan di destinasi tersebut.

Dari hasil tabel di atas, dengan demikian wisatawan yang berkunjung ke The Lodge Maribaya setuju bahwa tingkat attention paling tinggi ada pada item nomor 1, karena The Lodge Maribaya cukup aktif membagikan informasi dan memasang iklan mengenai destinasi wisatanya melalui online ads, seperti di website resmi www.thelodgemaribaya.com dan akun instagram resmi @thelodgemaribaya banyak penawaran khusus untuk yang datang ke The Lodge Maribaya (TLM), event-event menarik yang mampu menarik minat wisatawan datang ke The Lodge Maribaya juga ikut di infokan kepada followers-nya. Kemudian untuk di blog, biasanya para blogger yang pernah berkunjung ke TLM sering berbagi cerita melalui blog resmi mereka mengenai destinasi tersebut itu sebabnya banyak yang mengetahui atau melihat TLM melalui online ads.

\section{Hasil Penelitian pada sub-variabel Interest}

Hasil analisis interest pada pengunjung The Lodge Maribaya Lembang didasarkan pada rekap data tanggapan responden terhadap empat penyataan dari sub-variabel interest(ítem 4-7). Berikut ini adalah rekap data tanggapan responden terhadap keempat pernyataan dari interest. 
Tabel 4.11Analisis tanggapan Interest

\begin{tabular}{|c|c|c|c|c|c|c|c|c|}
\hline \multirow{2}{*}{ Pernyataan } & \multicolumn{5}{|c|}{ Tanggapan Responden } & \multirow{2}{*}{$\begin{array}{l}\text { Jumlah } \\
\text { Sampel }\end{array}$} & \multirow{2}{*}{$\begin{array}{l}\text { Skor } \\
\text { Total }\end{array}$} & \multirow{2}{*}{$\begin{array}{l}\text { Skor } \\
\text { Ideal }\end{array}$} \\
\hline & $\begin{array}{l}\text { SS } \\
(5)\end{array}$ & $\begin{array}{c}\text { S } \\
(4)\end{array}$ & $\begin{array}{l}\text { RG } \\
\text { (3) }\end{array}$ & $\begin{array}{l}\mathrm{TS} \\
(2)\end{array}$ & $\begin{array}{c}\text { STS } \\
(1)\end{array}$ & & & \\
\hline \multirow{2}{*}{$\begin{array}{l}\text { Saya tertarik untuk mengunjungi The } \\
\text { Lodge Maribaya karena pengalaman } \\
\text { wisatawan lain (Tourist Experience). }\end{array}$} & 81 & 17 & 0 & 2 & 0 & 100 & 477 & \multirow{2}{*}{500} \\
\hline & $81 \%$ & $17 \%$ & $0 \%$ & $2 \%$ & $0 \%$ & $100 \%$ & $95.4 \%$ & \\
\hline \multirow{2}{*}{$\begin{array}{l}\text { Saya tertarik untuk mengunjungi The } \\
\text { Lodge Maribaya karena atraksi photo } \\
\text { spots. }\end{array}$} & 85 & 13 & 0 & 2 & 0 & 100 & 479 & \multirow{2}{*}{500} \\
\hline & $85 \%$ & $13 \%$ & $0 \%$ & $2 \%$ & $0 \%$ & $100 \%$ & $95.8 \%$ & \\
\hline \multirow{2}{*}{$\begin{array}{l}\text { Saya tertarik untuk mengunjungi The } \\
\text { Lodge Maribaya karena sedang } \\
\text { popular/terkenal di internet dan jejaring } \\
\text { sosial. }\end{array}$} & 83 & 15 & 0 & 2 & 0 & 100 & 479 & \multirow{2}{*}{500} \\
\hline & $83 \%$ & $15 \%$ & $0 \%$ & $2 \%$ & $0 \%$ & $100 \%$ & $95.8 \%$ & \\
\hline \multirow{2}{*}{$\begin{array}{l}\text { Saya tertarik untuk mengunjungi The } \\
\text { Lodge Maribaya Karena pemandangan } \\
\text { alamnya. }\end{array}$} & 87 & 13 & 0 & 0 & 0 & 100 & 487 & \multirow{2}{*}{500} \\
\hline & $87 \%$ & $13 \%$ & $0 \%$ & $0 \%$ & $0 \%$ & $100 \%$ & $97.4 \%$ & \\
\hline \multicolumn{7}{|c|}{ Total skor } & 1922 & 2000 \\
\hline \multicolumn{7}{|c|}{ Persentase } & $96.3 \%$ & \\
\hline
\end{tabular}

Berdasarkan perhitungan pada tabel 4.11,tingkat interest paling tinggi ada pada item nomor tujuh sebanyak $97,4 \%$ bahwa wisatawan tertarik untuk mengunjungi The Lodge Maribaya karena pemandangan alamnya. Kemudian di posisi kedua tertinggi ada pada ítem nomor lima dan enam dengan jumlah persentase yang sama yaitu sebesar $95,8 \%$ yang menyatakan wisatawan tertarik mengunjungi The Lodge Maribaya karena atraksi photo spots dan juga karena sedang populer/terkenal di internet dan jejaring sosial. Selanjutnya sebesar $95,4 \%$ setuju dengan pernyatan ítem nomor empat, bahwa wisatawan tertarik untuk mengunjungi The Lodge Maribaya karena pengalaman wisatawan lain (Tourist Experiences).

Dari data tersebut, seperti yang dikatakan oleh Sugiyama dan Andree (2011) bahwa tahap interest adalah pesan komunikasi yang membangkitkan minat khalayak untuk mengetahui dan mengenal lebih lanjut tentang pesan tersebut atau tentang produk yang dikomunikasikan. Hasil tabel di atas, ketertarikan wisatawan terhadap the lodge maribaya karena destinasi ini memiliki pemandangan yang sangat indah dan juga memiliki atraksi unggulan yaitu photo spots, informasi tersebut mereka dapatkan melalui iklan dan unggahan wisatawan lain yang pernah datang ke TLM, yang tersebar di jejaring sosial dan mampu membangkitkan minat untuk mengetahui lebih lanjut lagi mengenai The Lodge Maribaya pada tahap selanjutnya yaitu tahap search.

\section{Hasil penelitian pada tanggapan Search}

Hasil analisis search pada pengunjung The Lodge Maribaya Lembang didasarkan pada rekap data tanggapan responden terhadap tiga pernyataan dari sub-variabel search (ítem 8-10). Berikut ini adalah rekap data tanggapan responden terhadap ketiga pernyataan dari search.

Tabel 4.12Analisis Tanggapan Search

\begin{tabular}{|c|c|c|c|c|c|c|c|c|}
\hline \multirow{2}{*}{ Pernyataan } & \multicolumn{5}{|c|}{ Tanggapan Responden } & \multirow{2}{*}{$\begin{array}{l}\text { Jumlah } \\
\text { Sampel }\end{array}$} & \multirow{2}{*}{$\begin{array}{l}\text { Skor } \\
\text { Total }\end{array}$} & \multirow{2}{*}{$\begin{array}{l}\text { Skor } \\
\text { Ideal }\end{array}$} \\
\hline & $\begin{array}{l}\text { SS } \\
(5)\end{array}$ & $\begin{array}{c}S \\
(4)\end{array}$ & $\begin{array}{c}\text { RG } \\
(3)\end{array}$ & $\begin{array}{l}\text { TS } \\
(2)\end{array}$ & $\begin{array}{c}\text { STS } \\
\text { (1) }\end{array}$ & & & \\
\hline
\end{tabular}




\begin{tabular}{|c|c|c|c|c|c|c|c|c|}
\hline \multirow{2}{*}{$\begin{array}{l}\text { Penelusuran informasi The Lodge } \\
\text { Maribaya di situs internet lebih mudah. }\end{array}$} & 85 & 15 & 0 & 0 & 0 & 100 & 485 & \multirow{2}{*}{500} \\
\hline & $85 \%$ & $15 \%$ & $0 \%$ & $0 \%$ & $0 \%$ & $100 \%$ & $97.0 \%$ & \\
\hline \multirow{2}{*}{$\begin{array}{l}\text { Saya memulai penelusuran mengenai } \\
\text { The Lodge Maribaya dengan } \\
\text { menggunakan mesin pencari (search } \\
\text { engine) agar tahu situs mana yang } \\
\text { informasinya lebih lengkap. }\end{array}$} & 79 & 18 & 0 & 3 & 0 & 100 & 473 & \multirow{2}{*}{500} \\
\hline & $79 \%$ & $18 \%$ & $0 \%$ & $3 \%$ & $0 \%$ & $100 \%$ & $94.6 \%$ & \\
\hline \multirow{2}{*}{$\begin{array}{l}\text { Saya dapat mengetahui jarak, fasilitas } \\
\text { dan harga masuk berkunjung ke The } \\
\text { Lodge Maribaya. }\end{array}$} & 73 & 21 & 0 & 6 & 0 & 100 & 461 & \multirow{2}{*}{500} \\
\hline & $73 \%$ & $21 \%$ & $0 \%$ & $6 \%$ & $0 \%$ & $100 \%$ & $92.2 \%$ & \\
\hline \multicolumn{7}{|c|}{ Total } & 1419 & 1500 \\
\hline \multicolumn{7}{|c|}{ Persentase| } & $94.6 \%$ & \\
\hline
\end{tabular}

Berdasarkan perhitungan pada tabel 4.12, tingkat search paling tinggi ada pada item nomor delapan sebanyak $97,0 \%$ bahwa penelusuran informasi The Lodge Maribaya di situs internet lebih mudah ditemukan. Kemudian di posisi kedua tertinggi ada pada ítem nomor sembilansebanyak 94,6\% yang menyatakan bahwa wisatawan melakukan penelusuran mengenai The Lodge Maribaya dengan menggunakan mesin pencari (search engine) agar tahu situs mana yang informasinya lebih lengkap. Selanjutnya sebesar $92,2 \%$ setuju dengan pernyatan ítem nomor 10 , bahwa wisatawan dapat mengetahui jarak, fasilitas dan harga masuk berkunjung ke The Lodge Maribaya setelah melakukan pencarían di internet.

Dari hasil tabel di atas, dengan demikian wisatawan yang berkunjung ke The Lodge Maribaya setuju bahwa tingkat search tertinggi ada pada item nomor delapan, karena The Lodge Maribaya mempunyai website khusus untuk membagikan informasi seputar kegiatan, atraksi, fasilitas, dan event yang mereka punya melalui situs resmi www.thelodgemaribaya.com, kemudian The Lodge Maribaya juga aktif membagikan informasi mengenai hal tersebut melalui akun resmi instagramnya yang bernama @ thelodgemaribaya dengan followers sebanyak 44.0 dan sebanyak 493 post di akun resminya. Hal tersebut yang membuat wisatawan dapat lebih mudah menemukan informasi mengenai The Lodge Maribaya melalui situs internet.

\section{Hasil penelitian pada tanggapan Action}

Hasil análisis action pada pengunjung The Lodge Maribaya Lembang didasarkan pada rekap data tanggapan responden terhadap dua belas pernyataan dari sub-variabel action (ítem 1122).Berikut ini adalah rekap data tanggapan responden terhadap keduabelas pernyataan dari action.

Tabel 4.13Analisis Tanggapan Action

\begin{tabular}{|c|c|c|c|c|c|c|c|c|}
\hline \multirow{2}{*}{ Pernyataan } & \multicolumn{5}{|c|}{ Tanggapan Responden } & \multirow{2}{*}{$\begin{array}{l}\text { Jumlah } \\
\text { Sampel }\end{array}$} & \multirow{2}{*}{$\begin{array}{l}\text { Skor } \\
\text { Total }\end{array}$} & \multirow{2}{*}{$\begin{array}{l}\text { Skor } \\
\text { Ideal }\end{array}$} \\
\hline & $\begin{array}{l}\text { SS } \\
(5) \\
\end{array}$ & S (4) & $\begin{array}{l}\text { RG } \\
(3)\end{array}$ & $\begin{array}{l}\text { TS } \\
(2) \\
\end{array}$ & $\begin{array}{c}\text { STS } \\
(1) \\
\end{array}$ & & & \\
\hline \multirow{2}{*}{$\begin{array}{l}\text { Saya memutuskan untuk mengunjungi } \\
\text { The Lodge Maribaya berdasarkan } \\
\text { informasi yang sudah didapat melalui } \\
\text { internet. }\end{array}$} & 86 & 14 & 0 & 0 & 0 & 100 & 486 & \multirow{2}{*}{500} \\
\hline & $86 \%$ & $14 \%$ & $0 \%$ & $0 \%$ & $0 \%$ & $100 \%$ & $97.2 \%$ & \\
\hline \multirow{2}{*}{$\begin{array}{l}\text { Saya memutuskan untuk mengunjungi } \\
\text { The Lodge Maribaya karena harganya } \\
\text { cukup terjangkau untuk semua kalangan. }\end{array}$} & 46 & 23 & 0 & 31 & 0 & 100 & 384 & \multirow{2}{*}{500} \\
\hline & $46 \%$ & $23 \%$ & $0 \%$ & $31 \%$ & $0 \%$ & $100 \%$ & $76.8 \%$ & \\
\hline \multirow{2}{*}{$\begin{array}{l}\text { Saya memutuskan untuk mengunjungi } \\
\text { The Lodge Maribaya karena jaraknya } \\
\text { mudah ditempuh. }\end{array}$} & 38 & 14 & 0 & 48 & 0 & 100 & 342 & \multirow{2}{*}{500} \\
\hline & $38 \%$ & $14 \%$ & $0 \%$ & $48 \%$ & $0 \%$ & $100 \%$ & $68.4 \%$ & \\
\hline Saya memutuskan untuk mengunjungi & 84 & 16 & 0 & 0 & 0 & 100 & 484 & 500 \\
\hline
\end{tabular}




\begin{tabular}{|c|c|c|c|c|c|c|c|c|}
\hline $\begin{array}{l}\text { The Lodge Maribaya karena fasilitasnya } \\
\text { sudah lengkap (tempat makan, parkir, } \\
\text { toilet dan mushola). }\end{array}$ & $84 \%$ & $16 \%$ & $0 \%$ & $0 \%$ & $0 \%$ & $100 \%$ & $96.8 \%$ & \\
\hline \multirow{2}{*}{$\begin{array}{l}\text { Saya memutuskan untuk mengunjungi } \\
\text { The Lodge Maribaya karena merupakan } \\
\text { destinasi wisata alam di Lembang. }\end{array}$} & 81 & 19 & 0 & 0 & 0 & 100 & 481 & \multirow{2}{*}{500} \\
\hline & $81 \%$ & $19 \%$ & $0 \%$ & $0 \%$ & $0 \%$ & $100 \%$ & $96.2 \%$ & \\
\hline \multirow{2}{*}{$\begin{array}{l}\text { Saya mengabadikan pengalaman ke The } \\
\text { Lodge Maribaya di atraksi photo spot } \\
\text { Sky Tree. }\end{array}$} & 64 & 11 & 0 & 25 & 0 & 100 & 414 & \multirow{2}{*}{500} \\
\hline & $64 \%$ & $11 \%$ & $0 \%$ & $25 \%$ & $0 \%$ & $100 \%$ & $82.8 \%$ & \\
\hline \multirow{2}{*}{$\begin{array}{l}\text { Saya mengabadikan pengalaman ke The } \\
\text { Lodge Maribaya di atraksi photo spot } \\
\text { Zip Bike. }\end{array}$} & 51 & 11 & 0 & 38 & 0 & 100 & 375 & \multirow{2}{*}{500} \\
\hline & $51 \%$ & $11 \%$ & $0 \%$ & $38 \%$ & $0 \%$ & $100 \%$ & $75.0 \%$ & \\
\hline \multirow{2}{*}{$\begin{array}{l}\text { Saya mengabadikan pengalaman ke The } \\
\text { Lodge Maribaya di atraksi photo spot } \\
\text { Moutain Swing. }\end{array}$} & 53 & 12 & 0 & 35 & 0 & 100 & 383 & \multirow{2}{*}{500} \\
\hline & $53 \%$ & $12 \%$ & $0 \%$ & $35 \%$ & $0 \%$ & $100 \%$ & $76.6 \%$ & \\
\hline \multirow{2}{*}{$\begin{array}{l}\text { Saya mengabadikan pengalaman ke The } \\
\text { Lodge Maribaya di atraksi photo spot } \\
\text { Gantole. }\end{array}$} & 51 & 11 & 0 & 38 & 0 & 100 & 375 & \multirow{2}{*}{500} \\
\hline & $51 \%$ & $11 \%$ & $0 \%$ & $38 \%$ & $0 \%$ & $100 \%$ & $75.0 \%$ & \\
\hline \multirow{2}{*}{$\begin{array}{l}\text { Saya mengabadikan pengalaman ke The } \\
\text { Lodge Maribaya di atraksi photo spot } \\
\text { Hot Air Balloon. }\end{array}$} & 53 & 13 & 0 & 34 & 0 & 100 & 385 & \multirow{2}{*}{500} \\
\hline & $53 \%$ & $13 \%$ & $0 \%$ & $34 \%$ & $0 \%$ & $100 \%$ & $77.0 \%$ & \\
\hline \multirow{2}{*}{$\begin{array}{l}\text { Saya mengabadikan pengalaman ke The } \\
\text { Lodge Maribaya di atraksi photo spot } \\
\text { Sky Plane. }\end{array}$} & 52 & 10 & 0 & 38 & 0 & 100 & 376 & \multirow{2}{*}{500} \\
\hline & $52 \%$ & $10 \%$ & $0 \%$ & $38 \%$ & $0 \%$ & $100 \%$ & $75.2 \%$ & \\
\hline \multirow{2}{*}{$\begin{array}{l}\text { Saya mengabadikan pengalaman ke The } \\
\text { Lodge Maribaya di atraksi photo spot } \\
\text { Hot Air Balloon Hydraulic. }\end{array}$} & 54 & 13 & 0 & 33 & 0 & 100 & 388 & \multirow{2}{*}{500} \\
\hline & $54 \%$ & $13 \%$ & $0 \%$ & $33 \%$ & $0 \%$ & $100 \%$ & $77.6 \%$ & \\
\hline \multicolumn{7}{|c|}{ Total } & 4873 & 6000 \\
\hline \multicolumn{7}{|c|}{ Persentase } & $81.2 \%$ & \\
\hline
\end{tabular}

Berdasarkan perhitungan pada tabel 4.13 , tingkat Action paling tinggi ada pada item nomor sebelas sebanyak $97,2 \%$ bahwa wisatawan memutuskan untuk mengunjungi The Lodge Maribaya berdasarkan informasi yang sudah didapat melalui internet. Kemudian di posisi kedua tertinggi ada pada ítem nomor 14 sebanyak 96,8\% yang menyatakan bahwa wisatawan memutuskan untuk mengunjungi The Lodge Maribaya karena fasilitasnya sudah lengkap seperti tempat makan, parkir, toilet dan mushola. Selanjutnya sebesar 96,2 $\%$ setuju dengan pernyatan ítem nomor 15 , bahwa wisatawan memutuskan mengunjungi The Lodge Maribaya karena merupakan destinasi alam di Lembang.

Menurut Sugiyama dan Andree (2011) bahwa tahap Action adalah pesan telah berhasil mendorong khalayak untuk melakukan tindakan tertentu, yang pada akhirnya dan efek terutama yang diharapkan dari setiap kegiatan komunikasi sebuah perusahaan adalah tindakan atau keputusan untuk membeli. Sesuai dengan pernyataan mengenai atraksi wisata photo spots yang ada di The Lodge Maribaya, kebanyakan wisatawan melakukan tindakan berupa berkunjung ke TLM kemudian mengabadikan pengalaman berkunjungnya dengan berfoto di atraksi photo spots. Photo spots yang paling banyak di abadikan melalui foto yaitu photo spot Sky Tree.

Dari hasil tabel di atas, dengan demikian wisatawan yang berkunjung ke The Lodge Maribaya setuju bahwa tingkat action tertinggi ada pada item nomor sebelas, karena sebelumnya wisatawan melakukan pencarían atau search terlebih dahulu melalui internet mengenai The Lodge Maribaya (TLM) sehingga wisatawan dapat 
mengetahui apa saja yang ada di TLM seperti harga tiket masuk, jarak tempuh ke TLM, Fasilitas yang ada disana dan atraksi wisata di The Lodge Maribaya. Kemudian, atraksi photo spot yang paling banyak diabadikan melalui foto oleh wisatawan adalah Sky Tree, karena Sky Tree adalah atraksi wisata photo spot yang pertama dibuat di The Lodge Maribaya dan masih menarik sampai sekarang didukung oleh share dari wisatawan lain yang mengunggah foto di Sky Tree melalui media sosialnya.

\section{Hasil penelitian tanggapan Share}

Hasil análisis share pada pengunjung The Lodge Maribaya Lembang didasarkan pada rekap data tanggapan responden terhadap enam pernyataan dari sub-variabel share (ítem 23-28). Berikut ini adalah rekap data tanggapan responden terhadap keenam pernyataan dari share.

Tabel 4.14Analisis tanggapan Share

\begin{tabular}{|c|c|c|c|c|c|c|c|c|}
\hline \multirow{2}{*}{ Pernyataan } & \multicolumn{5}{|c|}{ Tanggapan Responden } & \multirow{2}{*}{$\begin{array}{l}\text { Jumlah } \\
\text { Sampel }\end{array}$} & \multirow{2}{*}{$\begin{array}{l}\text { Skor } \\
\text { Total }\end{array}$} & \multirow{2}{*}{$\begin{array}{l}\text { Skor } \\
\text { Ideal }\end{array}$} \\
\hline & $\begin{array}{l}\text { SS } \\
(5)\end{array}$ & S (4) & $\begin{array}{l}\text { RG } \\
(3)\end{array}$ & $\begin{array}{l}\mathrm{TS} \\
(2) \\
\end{array}$ & $\begin{array}{c}\text { STS } \\
(1)\end{array}$ & & & \\
\hline \multirow{2}{*}{$\begin{array}{l}\text { Saya ingin membagikan cerita } \\
\text { pengalaman mengunjungi The Lodge } \\
\text { Maribaya ke teman/rekan. }\end{array}$} & 83 & 17 & 0 & 0 & 0 & 100 & 483 & \multirow{2}{*}{500} \\
\hline & $83 \%$ & $17 \%$ & $0 \%$ & $0 \%$ & $0 \%$ & $100 \%$ & $96.6 \%$ & \\
\hline \multirow{2}{*}{$\begin{array}{l}\text { Saya ingin membagikan cerita } \\
\text { pengalaman mengunjungi The Lodge } \\
\text { Maribaya melalui percakapan langsung. }\end{array}$} & 82 & 18 & 0 & 0 & 0 & 100 & 482 & \multirow{2}{*}{500} \\
\hline & $82 \%$ & $18 \%$ & $0 \%$ & $0 \%$ & $0 \%$ & $100 \%$ & $96.4 \%$ & \\
\hline \multirow{2}{*}{$\begin{array}{l}\text { Saya membagikan cerita pengalaman } \\
\text { mengunjungi The Lodge Maribaya } \\
\text { melalui situs jejaring sosial. }\end{array}$} & 87 & 13 & 0 & 0 & 0 & 100 & 487 & \multirow{2}{*}{500} \\
\hline & $87 \%$ & $13 \%$ & $0 \%$ & $0 \%$ & $0 \%$ & $100 \%$ & $97.4 \%$ & \\
\hline \multirow{2}{*}{$\begin{array}{l}\text { Saya membagikan cerita pengalaman } \\
\text { mengunjungi The Lodge Maribaya } \\
\text { melalui Youtube. }\end{array}$} & 18 & 8 & 0 & 74 & 0 & 100 & 270 & \multirow{2}{*}{500} \\
\hline & $18 \%$ & $8 \%$ & $0 \%$ & $74 \%$ & $0 \%$ & $100 \%$ & $54.0 \%$ & \\
\hline \multirow{2}{*}{$\begin{array}{l}\text { Saya membagikan cerita pengalaman } \\
\text { mengunjungi The Lodge Maribaya } \\
\text { melalui Facebook. }\end{array}$} & 44 & 9 & 0 & 47 & 0 & 100 & 350 & \multirow{2}{*}{500} \\
\hline & $44 \%$ & $9 \%$ & $0 \%$ & $47 \%$ & $0 \%$ & $100 \%$ & $70.0 \%$ & \\
\hline \multirow{2}{*}{$\begin{array}{l}\text { Saya membagikan cerita pengalaman } \\
\text { mengunjungi The Lodge Maribaya } \\
\text { melalui Instagram. }\end{array}$} & 84 & 6 & 0 & 10 & 0 & 100 & 464 & \multirow{2}{*}{500} \\
\hline & $84 \%$ & $6 \%$ & $0 \%$ & $10 \%$ & $0 \%$ & $100 \%$ & $92.8 \%$ & \\
\hline \multicolumn{7}{|c|}{ Total } & 2536 & 3000 \\
\hline \multicolumn{7}{|c|}{ Persentase } & $84.5 \%$ & \\
\hline
\end{tabular}

Berdasarkan perhitungan pada tabel 4.14, tingkat share paling tinggi ada pada item nomor 25 sebanyak 97,4\% bahwa wisatawan ingin membagikan pengalaman mengunjungi The Lodge Maribaya melalui situs jejaring sosial. Kemudian di posisi kedua tertinggi ada pada ítem nomor 23 sebanyak 96,6\% yang menyatakan bahwa wisatawan ingin membagikan pengalaman mengunjungi The Lodge Maribaya ke teman dan rekannya. Selanjutnya sebesar 96,4 \% setuju dengan pernyatan ítem nomor 24, bahwa wisatawan ingin membagikan pengalaman mengunjungi The Lodge Maribaya melalui percakapan langsung.

Pernyataan mengenai media sosial yang digunakan untuk membagikan cerita pengalaman mengunjungi The Lodge Maribaya, kebanyakan wisatawan membagikan pengalamannya melalui Instagram sebanyak 92,8\%. Kemudian yang kedua adalah Facebook sebesar 70,0\%. Selanjutnya, yang terakhir adalah Youtube sebesar 54,0\%. 
Dari hasil tabel di atas, menurut Sugiyama dan Andree (2011) bahwa tahap share yaitu Jika informasi yang didapat cukup baik dan menarik minat dari wisatawan, maka wisatawan akan berbagi kepada orang-orang di sekitarnya maupun membagikan pengalamannya melalui internet dan media sosial yang mereka punya. Disinilah akan tercipta sebuah perbincangan mengenai informasi dan pengalaman berwisata di The Lodge Maribaya tersebut baik melalui media online maupun secara langsung. Dengan demikian, dalam penelitian ini wisatawan yang berkunjung ke The Lodge Maribaya setuju bahwa tingkat share di situs jejaring sosial lebih cepat menyebarkan informasi dan lebih menarik secara visual karena dapat mengirimkan informasi berupa gambar maupun video dan dapat tersebar dengan jangkauan yang luas. Kemudian media sosial yang paling banyak digunakan wisatawan utuk membagikan cerita

Tabel 4.15 Nilai keseluruhan AISAS (Attention, interest, search, action, share) pada pengunjung

The Lodge Maribaya Lembang.

\begin{tabular}{|c|c|c|}
\hline No. & Sub-variabel & Persentase \\
\hline 1. & Attention & $95,9 \%$ \\
\hline 2. & Interest & $96,3 \%$ \\
\hline 3. & Search & $94,6 \%$ \\
\hline 4. & Action & $81,2 \%$ \\
\hline 5. & Share & $84,5 \%$ \\
\hline & $\begin{array}{c}\text { Nilai keseluruhan variable } \\
\text { AISAS }\end{array}$ & $\mathbf{9 0 , 5} \%$ \\
\hline
\end{tabular}

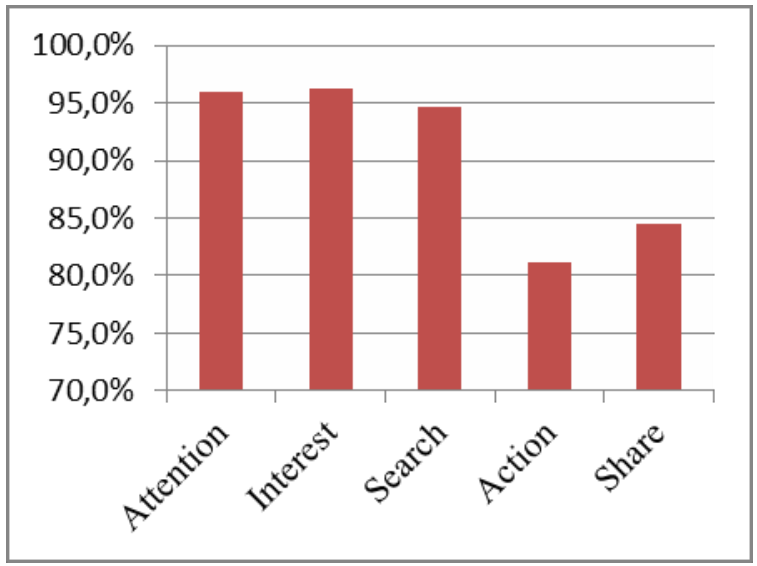

Gambar 4.1Grafik AISAS Secara Keseluruhan Berdasarkan gambar 4.1 di atas, grafik interest memiliki hasil presentase yang paling tinggi sebanyak 96,3\% diantara sub-variabel AISAS. Sedangkan data grafik action memiliki hasil presentase paling rendah diantara sub-variabel lainnya sebesar 81,2\%, hal itu dikarenakan sebanyak $48 \%$ menyatakan "tidak setuju" dengan pengalamannya adalah Instagram, karena di media sosial Instagram banyak fitur yang memudahkan penggunanya untuk berkreasi dalam hal membagikan cerita melalui unggahan foto maupun video yang nantinya akan bermanfaat bagi yang melihatnya.Tahap share akan lebih tinggi persentasenya apabila dari pihak The Lodge Maribaya memberikan intensif berupa promopromo menarik guna memotivasi pengunjung untuk yang sudah melakukan sharing di jejaring sosial.

Setelah membahas hasil rekap data tanggapan responden dari sub-variabel attention, interest, search, action dan share maka akan dilanjutkan dengan pembahasan hasil persentase secara keseluruhan AISAS pengunjung The Lodge Maribaya Lembang. Berikut ini adalah perhitungan persentase AISAS secara keseluruhan pada pengunjung The Lodge Maribaya Lembang.

pernyataan bahwa jarak ke The Lodge Maribaya mudah ditempuh. Hal tersebut yang menyenbabkan grafik sub-variabel action berada di posisi paling rendah.

\section{Kesimpulan dan Saran}

\section{Kesimpulan}

Berdasarkan hasil penelitian dan pembahasan dari bab sebelumnya, analisis AISAS pada pengunjung The Lodge Maribaya dapat disimpulkan bahwa setiap tahapan AISAS sudah diterapkan oleh pengunjung The Lodge Maribaya dan mendapat hasil dengan persentase tinggi diatas $80 \%$.

Pada tahap attention, pengunjung The Lodge Maribaya sudah banyak memperhatikan iklan mengenai The Lodge Maribaya lembang melalui online ads seperti website, akun instagram, facebook dan jejaring sosial lainnya, selain itu pengunjung juga sudah mengetahui produk unggulan TLM seperti photo spots dan camping ground dan pengunjung juga dapat menggunakan fitur live chat sebagai layanan untuk berkomunikasi dengan pihak pengelola di website tersebut agar bisa mendapatkan informasi mengenai TLM. Tahap interest pada pengunjung The Logde Maribaya, sebagian besar wisatawan tertarik dengan pemandangan alam dan produk unggulan yaitu photo spots yang ada The Lodge Maribaya (TLM) berdasarkan informasi yang mereka dapat melalui internet berupa gambar maupun video di TLM. Tahap Search, pengunjung The Lodge Maribaya sudah melakukan penelusuran di situs internet guna mendapatkan informasi TLM mengenai jarak, fasilitas, harga tiket masuk dan event-event yang ada disana. The Lodge Maribaya cukup sering membagikan infomasi mengenai hal tersebut melalui website dan akun resminya. Tahap 
Action, pengunjung The Lodge Maribaya memutuskan untuk mengunjungi TLM berdasarkan informasi yang telah mereka dapat melalui internet, selain itu pengunjung juga mengabadikan pengalaman berkunjungnya di atraksi photo spots yang telah disediakan, akan tetapi masalah jarak tempuh menuju TLM masih kurang layak untuk dilalui oleh pengunjung yang datang. Pada tahap share, pengunjung The Lodge Maribaya banyak melakukan sharing melalui situs jejaring sosial karena lebih cepat menyebar informasi dan lebih menarik secara visual, karena penyebaran informasinya dapat berupa foto dan video, Intagram menjadi media sosial yang paling banyak digunakan untuk penyebaran informasi TLM. Akan tetapi masih banyak pengunjung yang enggan untuk melakukan sharing di jejaring sosialnya seperti di Youtube, karena masih sedikit yang mempunyai akun personal di Youtube.

Penelitian AISAS pada pengunjung The Lodge Maribaya secara keseluruhan sudah dilakukan secara bertahap mulai dari tahap awal yaitu attention sampai tahap akhir yaitu share. Dengan demikian, hasil penelitian ini menyatakan bahwa pengunjung The Lodge Maribaya sudah sebagaian besar menerapkan proses tahapan AISAS dalam perilaku berkunjung mereka.

\section{Saran}

Berdasarkan kesimpulan diatas, adapun saran yang peneliti ajukan :

1. Hasil analisis mengenai Action lebih rendah dibandingkan keempat sub-variabel lainnya (attention, interest, search, dan share) menjadi pertimbangan bagi pihak The Lodge Maribaya agar segera membenahi masalah jarak tempuh ke TLM, dengan cara bekerja sama dengan pihak pemerintah agar dapat memperlebar jalan, membuat sengkedan sebagai upaya pencegahan tanah longsor yang cukup sering terjadi di jalan menuju destinasi wisata dan memperbaiki kontur jalan yang sudah rusak agar lebih nyaman untuk dillalui oleh pengunjung. Dengan begitu informasi di internet mengenai jarak tempuh ke TLM tidak akan menjadi masalah lagi untuk yang akan berkunjung ke TLM.

2. The Lodge Maribaya sebaiknya memberikan intensif berupa promo untuk pengunjung yang melakukan sharing di jejaring sosial. Sharing tersebut dapat berupa dokumentasi foto, video, maupun tulisan mengenai perjalanan wisata ke TLM.Hal tersebut akan membuat pengunjung termotivasi untuk menyebarkan informasi tentang The Lodge Maribaya ke jejaring sosial, dan yang melihat sharing tersebut akan tertarik untuk berkunjung ke TLM.

\section{DAFTAR PUSTAKA}

Gunn, Clare and Turgunt Var. 2002. Tourims planning Basic, Concepts, cases. New York: Routledge

Gunn, Clare and Turgunt Var. 2002. Tourims planning Basic, Concepts, cases. New York: Routledge

Hermantoro, Henky. 2015. Kepariwisataan, Destinasi Pariwisata, Produk Pariwisata. Depok (ID): Aditri.

Jogiyanto., 2009. Sistem teknologi informasi: edisi III. Yogyakarta (ID): Andi

Jogiyanto., 2009. Sistem teknologi informasi: edisi III. Yogyakarta (ID): Andi

Sugiyama, Kataro, Andree, Tim. 2011. The Dentsu Way. Mcgraw-Hill Ebooks.Thurau, Gwinner, Walsh Dan Gremler.

Sugiyono. 2017. Metode Penelitian Kuantitatif, Kualitatif, Dan R\&D. Bandung (ID): Alfabeta. 